\title{
Introduction to the Handbook of Research on Retailing
}

Over the last five years the pace of change in the retail industry has undeniably accelerated. Not only do many established retailers face declining sales, rising costs, and unsatisfied consumers, increased consumer spending at new discount rivals and ecommerce sites are forcing middle-market, big-box retailers to scrutinize their finances, resulting in an unseen number of store closures. In 2017, for example, Macy's announced they were closing up to 100 stores, and J.C. Penney and Sears both planned to close almost up to 140 and 150 stores, respectively (Wahba 2017a, 2017b). These are just some of the most visible examples of what business analysts have coined the 'Amazon Effect' as consumer spending migrates from brick-and-mortar stores to the online realm. The ultimate question is: Are these closures the symptom of an industry-wide meltdown, or merely a sign of painful, yet creative destruction? One thing we know for sure: consumers are not spending less. On the contrary, in the first four months of 2017 retail industry spending rose by 3.6 percent compared with the same period in 2016, whereby expectations are that growth will pick up even more (Wahba 2017b). The retail pie is therefore not shrinking and, rather than a retail-apocalypse, we seem to be witnessing a shift in where and how consumers shop; a shift that is most likely irrevocable. In any case, this implies that even currently successful companies cannot afford to sit back and relax, but need to prepare for the next wave of change.

These transformative times may therefore be the best possible moment to take stock and reflect on what we currently know about best retail practices, and how academic insights can further strengthen retailers. To that end, we provide an overview of the current knowledge base that touches upon all aspects of retailer tactics and strategies. We acknowledge that most of the extant work is based on the brick-andmortar universe. Nevertheless, by laying out the basic principles of how consumers act and retailers react, we hope to provide a clear and insightful path forward, not only on how to compete and thrive in the physical world, but also to transcend and translate these insights to the digital sphere.

Before presenting and introducing the different chapters in this book, we first take some time to reflect on the future of retail. Do brick-and-mortar 


\section{Handbook of research on retailing}

retailers really have to fear a dystopian future or are reports about the death of physical retail greatly exaggerated?

\section{1 THE STORE IS DEAD(?)}

The retail scene has been under great turmoil over the past decade. Undeniably, the biggest culprit is the consumer: consumers' mindsets and attitudes have changed for good.

For one, the Great Recession has impacted consumers, keeping the weight of the economy on their minds and leading to a severe case of pricediscount addiction. The recession, combined with the rise of digital juggernauts and smartphones as shopping tools, has pitted retailers against one another in a never-ending price war (Wahba 2017b). Not only does the constant discounting drive down margins, it also trains consumers to shop on deal. Moreover, there is a spending shift from goods to services: consumers do not want to own as much, they are looking for experiences rather than just a product (Halzack 2016). In addition, digitalization has transformed the way consumers think about service, assortment and convenience (BCG 2017).

In sum, the Consumer 2.0 wants it all: quality and quantity, at the time and place of his choice, at the lowest (or no) cost and no effort. These consumer demands, combined with technological advances, have led to a 'retailscape shakeout', in which traditional stores have been attacked from above as well as below.

\section{I.1.1 Attacks from the Clout: The Rise of Online}

Undeniably, the biggest 'disruption' has come from the advent of online players. In 2016, retail e-commerce sales worldwide amounted to 1.86 trillion US dollars and e-retail revenues are projected to grow to 4.48 trillion US dollars in 2021 (Statistica 2017). In total, online shopping accounted for 2 percent of grocery sales in 2016. Among the digital disruptors, Amazon is unquestionably the major culprit. Although Amazon started as an online bookseller in 1994, the company quickly diversified into a wide range of product categories, covering almost all consumer goods, showing astounding growth figures and 'dwarfing' many of the traditional retail players. Now Amazon Global's total banner sales exceed \$120 billion (compared to, for instance, 507 billion for Walmart; and in the same order of magnitude as Costco and Carrefour), and this figure is expected to more than double by 2022 (Planet Retail 2017a). With Amazon as the 'major disruptor', a surge of other pure-play online retailers have followed 
suit around the globe (like Alibaba and JD.com in China, or Zalando, Bol.com and Ocado in Europe - to name just a few), operating in a broad range of product categories (from electronics to lifestyle and fashion items and groceries).

From the consumer's perspective, the business proposition of these online players appears hard to beat at first glance. With their 'endless aisles' (no shelf-space restrictions) and help from third-party affiliates, online retailers can operate and present huge assortments, including products 'in the long tail', without having to buy and hold inventory for each and every product. For instance, Amazon's offer encompasses about 50 million SKUs, compared to only 2 million for Walmart (Planet Retail 2017b). Combined with ease of navigation (through search engines and personalized filters), and individual-tailored suggestions (based on recommendation systems), online holds the promise of giving consumers the exact product they want without the hassle of search costs or choice overload. Moreover, the availability of online price-comparison algorithms makes it easier for consumers to identify the cheapest items and best 'deals'. Lastly, online retailers promise home delivery within a short time span. For instance, to consumers with a 'Prime' subscription, Amazon would guarantee free delivery within two days.

As such, it seems that online players could give the Consumer 2.0 exactly what he wants, right there and now, at the lowest price, and without any effort ('from couch to couch').

\section{I.1.2 Attacks from Below: The Rise of the Hard Discounters and Online Private Label Lines}

Since their inception, Hard Discounters (HDs), with Aldi and Lidl as prime exemplars, have shown impressive growth figures in many European countries and, more recently, have made inroads into the US market. On a global level, both Aldi and Lidl now rank in the top ten of grocery retailers with 2017 sales levels exceeding 80 billion USD for each chain (Planet Retail 2017c); and the Schwarz Group (owner of Lidl) is expected to become the runner-up to Walmart as a global retailer power house by 2021 (Planet Retail 2017c).

With their unique business model based on three pillars: (i) simple, private label-dominated assortments (to cut costs and facilitate choice) with quality levels (claimed to be) on a par with national brands (NBs); (ii) sold at rock-bottom prices (on average: 50 percent below NBs at traditional chains); and (iii) in small, conveniently located stores, these players conquered the 'hearts and minds' of many consumers, across all socio-economic layers of the population (Kumar and Steenkamp 2009). 


\section{Handbook of research on retailing}

As consumers become ever-more value conscious (Nielsen 2011), cheap is the new smart. This puts traditional chains in a difficult spot: given that they already operate on tight margins, and are much less lean, they find it hard to beat or even match HD prices. Moreover, the HD threat is not limited to the grocery sector, but has extended well into other sectors, as exemplified by Lidl's recent introduction of the exclusive Heidi Klum clothing range.

In addition, in the private label realm, the domain where traditional retailers usually could make their value mark, retailers are also increasingly threatened by both hard discounters and digital retailers. Until recently, private labels under-indexed online. This is about to change as digital powerhouses like Amazon are fiercely entering the private label arena in many product categories, including computer accessories, home goods, pet supplies, and many more (Perez 2017). Recently, Amazon started the development of eight apparel private label lines to compete with fast fashion competitors upfront. Moreover, by adopting the Whole Foods brands in the grocery categories, Amazon can roll out private label brands online that already have extensive brand recognition. Needless to say, these private labels allow Amazon to put pressure on traditional retailers' margins and challenge them to match lower price points.

\section{I.1.3 The Death of the Traditional Store?}

The combined pressures from these new channels and formats have led many to pass a death sentence on traditional brick-and-mortar stores - an observation that is fueled by the wave of store closures among established traditional retailers. Moreover, it has led some to believe that traditional retail problems - often linked with managing physical stores - and their solutions have become obsolete. But have they?

Reports about the death of retail may indeed be greatly exaggerated. Since online shopping arrived in the 1990s, many repeatedly predicted the demise of brick-and-mortar. Still, it turns out that consumers are, after all, human. They often want a personal experience when they shop. Under the right circumstances, consumers still like to shop in stores. In the end, 'there aren't store customers or online customers - there are just customers who are more empowered than ever to shop on their terms', as Erik Nordstrom's, co-president stated (Kapner 2017). The ultimate litmus test therefore becomes: Who can serve these newly empowered consumers better? Does it matter to consumers whether you are a traditional brickand-mortar retailer or a digital native? Are shoppers truly satisfied by all things digital or discount? 


\section{I.2 THE STORE IS DEAD ... OR IS IT?}

Time for a reality check. Several years after the advent of the disruptors, let's consider the facts, and revisit the prospects for the physical store.

Despite this promising outlook, the share of online sales has not yet reached double-digit numbers. In 2016, e-commerce represented only 7.3 percent of overall US retail sales. While it absolutely boomed in sectors like entertainment, apparel and appliances (Bronnenberg and Ellickson 2015), the figures for the grocery sector - which still represents about 40 percent of global retail business, are much lower, halting at a meager 2-3 percent. Why is that so?

For online retailers, the business model as it stands now appears less profitable and sustainable than hoped for. In 2017, Amazon quarterly profits fell by 77 percent even as sales jumped, a sign of the significant costs in realizing its retail promises (Stevens 2017). For instance: the 'Prime delivery service' at Amazon led to a dramatic rise in shipping costs $(+37$ percent in one year) that outpaced the rise in revenue $(+22$ percent). Delivery is especially problematic for groceries, as these are low-margin orders and logistically very complex. Very short delivery times are called for, yet consumers do not want to pay delivery fees, and orders can include perishable and non-perishable items such that vans need up to three temperature zones. For other products like apparel, the costs of reverse logistics associated with product returns can become prohibitive.

In addition, from the consumers' point of view, downsides of the online channel are, after all, delivery inconvenience (especially for groceries, where consumers want items fast but are not willing to wait at home), lack of personal contact and the 'experience' of shopping and, given that it is impossible to physically inspect products prior to the purchase, receiving products that do not meet expectations (especially for products like apparel or fresh food, which are hard to 'evaluate' at a distance).

Together, these issues are known as the 'Last mile problem', which reveals to be a major impediment to online channel profitability and sustainability across many product categories (Thomasson and Vidalon 2013).

Similarly, though hard discounters may gain substantial ground in all the markets they enter, it remains highly unlikely that they will ultimately drive out traditional retail. Two phenomena come into play here. One is that of 'shopper bifurcation', that is, a divide of consumers into a segment of value-conscious shoppers, next to a persistent segment of (typically more wealthy) 'aspirational' shoppers who exclusively patronize highend stores and are not attracted to the discount format (Schwarz 2015). 
Whereas hard discounters may substantially tap into the value-conscious segment, they can only appeal to the aspirational shoppers by straying from their original concept. Adding assortment and improving store atmospherics may indeed help to attract the more aspirational-driven consumer, but comes at the risk of alienating their core value shopper and jeopardizing the low-cost concept.

The second phenomenon is that of within-shopper duplicity: even value-conscious consumers typically trade down for some products, but want 'the best of the best' and/or value a pleasant shopping experience for others, thus procuring only part of their basket at (hard) discount chains (Vroegrijk et al. 2013). In the end, hard discounters may even be perceived as complements rather than substitutes to traditional retailers, with consumers who turn to hard discounters for staples keeping more disposable income available to 'indulge' at other retailers. As some would argue, the ideal location for a new Aldi would be the parking lot of Walmart. In all, this implies that there are boundaries to the potential of the HD format, and that the outlook for traditional chains is not all that bleak.

\section{I.3 THE STORE IS DEAD - LONG LIVE THE STORE!}

In the face of these realities, it seems that the traditional brick-and-mortar stores are not extinct and can still claim an important role. New solutions for unmet needs regarding convenience, service, experience and assortment often involve the physical store. Traditional retailers have to play their trump cards, by differentiating from their challengers, but also by engaging in omnichannel or omni-format operations, alone or in cooperation with other players.

Practitioners and academics alike have come to recognize the role of physical store outlets in resolving the issues associated with the online channel. Walmart's Vice Chairman Eduardo Castro-Wright, for instance, sees its store estate as key for successful e-commerce fulfillment and stated: 'It's time to leverage our size and global footprint to take advantage of this evolving customer trend' (Walmart 2010). This can be done in several ways.

The store as a location for pick up and return. While home-delivery used to be the dominant fulfillment model, retailers are increasingly turning to 'click and collect' fulfillment to resolve the Last Mile Problem. With 'click and collect', also referred to as 'Buy online Pick up in Store' (BoPs), consumers place their order online (after which it is assembled by the retailer's personnel), and collect it later on at the retailer's physical facility at the time of their choosing (Planet Retail 2014). This physical facility 
can be a regular store, but also a conveniently located 'drive-through' pick-up point. Consumers may find this new fulfillment model a convenient way to acquire their online orders, especially for grocery purchases. Traditional (grocery) retailers, who ventured online, find the economics of this business model more appealing than home delivery, as they can capitalize on their physical store presence. But also pure-online retailers increasingly appreciate the importance of stores as a location for pick up and return, and team up with players that have a brick-and-mortar network in place - prominent examples being JD.com setting up a partnership with Walmart in China. More recently, Amazon's acquisition of Wholefoods provided a store network enabling Amazon to stockpile merchandise in numerous locations near the shopper and allowing for new pickup points. In addition, product returns inherently drive additional traffic to Whole Foods stores, providing an easy way to push customers who do not currently shop at Whole Foods to go into the store and see its lower prices - putting further pressure on retailers to compete with this mechanism for customer and Prime member acquisition. Combined with its existing warehouses and transportation network, this will certainly enhance Amazon's logistical capabilities and ability to provide consistent same-day delivery.

Interestingly, the intrinsic unmet need for more convenient pick-up opportunities leads to the creation of even more add-on channels that almost literally follow the footsteps of the consumer. CVS, for example, decided to roll out automated retail vending machines to catch busy consumers on the go in need for necessities, in locations such as airports and hotels. In a similar vein, the Fast Retailing Group plans to roll out vending machines selling heat-retaining shirts and lightweight jackets in airports and shopping malls.

The store as an experience center. Websites cannot give you 'goosebumps' and that is where physical stores still have an advantage, says Buron Carlock, Head of PwC US Real Estate Practice (Wigglesworth 2017). Compared to online, an important upside of the brick-and-mortar channel is that it allows consumers to physically inspect and 'try' products, and enjoy a real-life shopping environment. To capitalize on this advantage, retailers are increasingly refurbishing their stores into experience centers, with less space assigned to product storage on the shelves, and more room for/attention to personalized service or atmospherics. The store of the future will become less of a traditional 'transaction' center and more of an 'experience' center, and curated much like an exhibit. The unpleasant parts of in-person shopping, like checking out, will be eliminated as much as possible. Examples of such initiatives are Carrefour's revolutionary store concept in Milan, offering free wifi and 
charging stations for mobile devices, and featuring a lounge area and a bar where Happy Hour drinks are served; and 'Barnes \& Noble Cafe', a coffee corner area within the store for consumers to check out products in a relaxed atmosphere. Ultimately, this may lead to new concepts eliminating inventory in the store altogether. Following the lead of retailers such as Bonobos, Nordstrom for example decided to open showroom-like locations that offer services such as manicures, personal stylists and on-site tailoring, but carry no inventory at all, thereby trying to win back consumers who migrated online (Kapner 2017).

In addition, new services may be added to the store to further enhance the overall experience and stimulate repeat behavior and ultimately loyalty. Best Buy, for example, started using salespeople to visit consumers inside their homes and recommend electronics. The company hopes this will help drive sales at a time where fewer consumers visit stores, and as such unlock latent demand (Safdar and Stevens 2017). Interestingly, this move is followed by traditional retailers like Amazon, which is sending its employees into consumers' homes to provide free smart home consultations.

\section{I.4 SUMMARY AND FUTURE OUTLOOK}

Consumers have increasingly become multiple-store shoppers. They (judiciously) spread their purchases across different stores and formats (Inman et al. 2004; Vroegrijk et al. 2013), and often use savings on some products, to trade up on others. Moreover, consumers differ in their aspirational levels, a divide that is becoming more striking in developed and developing markets alike ('The Hour Glass Economy', Truss 2011). This implies there is room for 'cohabitation', upscale and discount stores, as well as online and physical stores, benefiting from and exploiting their complementarity. It also means that for traditional stores to thrive, they need to focus on differentiation, by offering higher service, and shifting emphasis to product categories and brands that cater to consumers' need to indulge or trade up, and - again - turn their store into a 'fun' shopping place. Leading players have come to realize this by 'upgrading' the store offer (e.g. Walmart's superstores flagging an extensive organic fresh-food assortment) or playing around with distinct aisles for upscale vs. discount products (e.g. Carrefour).

The traditional store continues to be the procurement channel of choice in many product categories, for many consumers. Moreover, the boundaries are blurring. While 'showrooming' may enhance the role of the physical store by allowing the touch and feel of products, 
brick-and-mortar retailers should also be wary of 'subsidizing' online rivals in categories where online ordering and delivery is frictionless, and should make sure not to lose the convenience-oriented shopper who seeks to efficiently acquire less upscale but 'good-value-for-money' items. Conversely, pure-online players enhancing the consumers' online experience and ability to check out products digitally ('webrooming'), should hedge against consumers engaging in ROPO (research online, purchase offline) behavior, by offering their own physical pick-up points.

Omnichannel has become the path forward. Traditional brick-andmortar players are expanding their online operations or teaming up with e-commerce retailers (e.g., Walmart and JD.com), and/or setting up their own discount banners (e.g., Carrefour through its Erteco stores in France). The power houses of online retail, like Amazon and JD.com, are getting a foot on firm ground, by acquiring or developing physical facilities, or joining forces with brick-and-mortar players. Hard Discounters like Aldi and Lidl, besides being somewhat caught up in the Wheel of Retailing, are venturing into online business (Forbes 2017).

Each of these players will try to serve the demands of the Consumer 2.0. Many of the previous challenges remain, but now get a different flavor. As a retail analyst put it: 'The Holy Grail for retailers remains the same - to ensure true continuity of consistent and delightful customer experience', Planet Retail 2017c). The current retailing scene will offer consumers a broader menu of options, and allow them to pick the combination that suits them for that product, at that time and place.

Finally, it may be useful to reflect on how these trends may ultimately influence branded goods manufacturers. Brands are increasingly under attack. Not only are they facing a new challenge as supermarket shoppers go generic, but also the shift from in-store shopping to online has left them more vulnerable to Amazon's growing dominance. About 55 percent of all product searches now start at Amazon, compared with 28 percent through search engines such as Google (Stevens 2017). As a consequence, Amazon will lean more and more on suppliers to help them make good on their lower price promise. This will likely trigger similar requests across the industry as major rivals aim to maintain their relative price positioning. Walmart, for example, told suppliers that its prices should be 15 percent lower than its competitors' 80 percent of the time, once again challenging brands because other retailers will ask suppliers to match (Gasparro et al. 2017).

In the face of this complexity, it is all the more important to take stock of current knowledge, based on insights and experience from leading scholars in the field. What do we know from extant studies, and what are the ensuing best practices? What evolutions are ahead, and will current 
recipes still work in the face of these changes? The chapters that follow shed light on these issues.

\section{I.5 OVERVIEW OF THE BOOK}

The book consists of 19 chapters, organized into seven parts. The first part sets the stage, by documenting important shifts in the retail scape. In Chapter 1, Bart Bronnenberg highlights how changes in consumers' time availability and lifestyles, along with technological evolutions, have increased the quest for convenience and the possibilities for retailers to offer such convenience. Chapter 2, by Jan-Benedict Steenkamp, paints a clear picture of the hard discount format, along with its success drivers and the ensuing challenges for traditional retail chains.

Part II revisits the role of pricing and promotions in the face of these changes. In Chapter 3, Mark Vanhuele highlights the perspective of the consumer and brings together current insights into shoppers' price perceptions and price knowledge. This chapter serves as a stepping stone for retailers' price-related actions. Zooming in on tactical issues, Chapter 4, by Karen Gedenk, takes stock of the extensive literature on retailer sales promotions, uncovering which actions have proven more or less successful and why. In Chapter 5, Ruth Bolton and Venkatesh Shankar consider the strategic aspect of pricing, identifying current and future pricing challenges, and how they can be met. A key price-related concept for retailers is their overall perception of being cheap or expensive. Chapter 6, by Alexander Chernev and Ryan Hamilton, sheds light on how price images are formed and can be managed by retailers.

As highlighted in the introduction, product assortment and fulfillment will continue to be key drivers of consumers' shopping behavior and retailer selection. Part III addresses these issues. In Chapter 7, Edward Fox underscores the dynamics of consumers' product and assortment choices - highlighting the sequential nature of purchase and consumption decisions, and how it affects the role of assortment in consumer store choice. Raj Sethuraman, in Chapter 8, offers a novel perspective on the national brand-private label interface, and uncovers how alternative consumer preference distributions translate into successful private label strategies. Chapter 9, by Els Breugelmans, Els Gijsbrechts and Katia Campo, zooms in on consumer reactions to various types of product unavailability, and elaborates on (proven or to-be-explored) management actions to limit the negative consequences of such unavailability. Finally, in Chapter 10, Andrew Petersen and Aydın Alptekinoğlu deal with the 
ever-more important problems of product fulfillment and the management of product returns - establishing current knowledge and identifying future challenges.

Part IV brings together extant insights on In-Store Marketing - a topic of continued importance not only because the physical store is far from extinct, but also because of its relevance for setting up successful online store environments and creating customer experience. In Chapter 11, Anne Roggeveen and Dhruv Grewal provide an overview of various in-store instruments, including emerging possibilities from the rise of omnichannel and mobile. Jeffrey Parker and Anthony Koschmann, in Chapter 12, focus on shelf layout, and how it influences consumers' information collection and choice both offline and online.

With Customer Engagement becoming more critical as the number of shopping options grows, Part V is dedicated to this topic. In Chapter 13, Rishika Rishika and Ramkumar Janakiraman discuss the role of social media, what drives their impact, and how retailers can take advantage of social media activities to improve performance. Werner Reinartz and Peter Linzbach, in Chapter 14, summarize available insights on the ability of reward programs to 'loyalize' consumers - thereby uncovering best practices and future challenges.

While Parts II to V focus on specific retailer instruments, Part VI considers broader strategic issues. Óscar González-Benito, Mercedes Martos-Partal and Álvaro Garrido-Morgado deal with retailer format decisions in Chapter 15. In Chapter 16, Zhiling Bei, Katrijn Gielens and Marnik Dekimpe zoom in on retailer entry and exit strategies, and assess how these marketing dynamics not only impact own retailer performance but also rivals and consumer welfare. In the next chapter, Chapter 17, Brian Ratchford and Dinesh Gauri investigate how retailers can enhance their productivity - issues that become critical in the face of rising fulfillment costs and increased pressure on profitability.

Part VII, finally, considers the interface between the retailer and his 'counterpart' in the supply chain: the manufacturer. Though the increasing exigence of the Consumer 2.0 puts the retailer under pressure, his position in the supply chain is not necessarily under siege. In Chapter 18, Inge Geyskens elaborates on the forces that affect the retailer-manufacturer power balance, and will shape the strength of the retailer's position in the future. Chapter 19, by Murali Mantrala and Omid Kamran-Disfani, elaborates on the importance of category management and discusses the role of category captains in establishing a fruitful collaboration between retailers and their suppliers. 


\section{Handbook of research on retailing}

\section{REFERENCES}

BCG (2017), 'The Digital Future: A Game Plan for Consumer Packaged Goods', Boston Consulting Group, Report, accessed September 27, 2017 at https://www.bcgperspectives. com/content/articles/digital_economy_consumer_products_digital_future_game_plan_ consumer_packaged_goods/?chapter $=6$.

Bronnenberg, Bart J. and Paul B. Ellickson (2015), 'Adolescence and the Path to Maturity in Global Retail', Journal of Economic Perspectives, 29 (4), 113-34.

Forbes, Thom (2017), 'Aldi Will Test Home Delivery Through Instacart in Three Cities', The Telegraph, August 14, accessed September 20, 2017 at https://www.mediapost.com/publications/article/305723/aldi-will-test-home-delivery-through-instacart-in.html?edition=104654.

Gasparro, Annie, Sarah Nassauer and Heather Haddon (2017), 'Big Food Pressed on Prices', The Wall Street Journal, September 1.

Halzack, Sarah (2016), 'Shoppers are Choosing Experiences over Stuff, and That's Bad News for Retailers', The Washington Post, January 8, accessed September 20, 2017 at https:// www.washingtonpost.com/business/economy/shoppers-are-choosing-experiences-overstuff-and-thats-bad-news-for-retailers/2016/01/07/eaa80b5a-b4a7-11e5-a76a-0b5145e86 79a_story.html?utm_term=.baeaeb38bdcf.

Inman, J. Jeffrey, Venkatesh Shankar, and Rosellina Ferraro (2004), 'The Roles of Channel-Category Associations and Geodemographics in Channel Patronage', Journal of Marketing, 68 (2), 51-71.

Kapner, Suzanne (2017), 'Nordstrom's Store Gamble', The Wall Street Journal, September 11.

Kumar, Nirmalya and Jan-Benedict E.M. Steenkamp (2007), Private Label Strategy: How to Beat the Store Brand Challenge. Boston, MA: Harvard Business School Press.

Nielsen (2011), 'The Rise of the Value Conscious Shopper: A Nielsen Global Private Label Report', The Nielsen Company, March.

Perez, Sarah (2017), 'Amazon's Private Label Business is Booming Thanks to Device Sales, Expanded Fashion Lines', TechCrunch.com accessed September 20, 2017 at https://techcrunch.com/2017/08/16/amazons-private-label-business-is-booming-thanks-to-devicesales-expanded-fashion-lines/.

Planet Retail (2014), 'Drive Format 2014, Driving in the Fast Lane', PlanetRetail.net report, February.

Planet Retail (2017a), Statistics, accessed September 20, 2017 at https://www.planetretail.net/ Retailers/4778/FinancialAnalysis.

Planet Retail (2017b), 'Amazon Strikes Back in the Cost versus Convenience War', Planetretail.net, February 21.

Planet Retail (2017c), 'Brick, Clicks \& Marketplaces: A 21st Century Roadmap for Digital Transformation', PlanetRetail.net Report.

Safdar, Khadeeja and Laura Stevens (2017), 'Gadget Sellers Make House Calls', The Wall Street Journal, August 29.

Schwarz, Nelson (2015), 'The Economics (and Nostalgia) of Dead Malls', The New York Times, January 3.

Statistica (2017), accessed September 20, 2017 at https://www.statista.com/statistics/379046/ worldwide-retail-e-commerce-sales/.

Stevens, Laura (2017), 'Amazon's Expansions Costs Take a Toll as profits Fall 77\%', Wall Street Journal, July 28.

Thomasson, Emma and Dominique Vidalon (2013), 'Analysis: Retailers Look to Click and Collect Online Profits', Reuters, September 6, accessed September 20, 2017 at http:// mobile.reuters.com/article/idUSBRE9850DC20130906?irpc=932/.

Truss, Elizabeth (2011), 'Time is Running Out for our Hourglass Economy', The Telegraph, October 25.

Vroegrijk, Mark, Els Gijsbrechts, and Katia Campo (2013), 'Close Encounter with the Hard Discounter: A Multiple-Store Shopping Perspective on the Impact of Local HardDiscounter Entry', Journal of Marketing Research, 50 (5), 606-26. 
Wahba, Phil (2017a), 'J.C. Penney is Closing 138 Stores this Sprig', Fortune, March 17, accessed September 20, 2017 at http://fortune.com/2017/03/17/jcpenney-stores-closing/.

Wahba, Phil (2017b), 'The Death of Retail is Greatly Exaggerated', Fortune, June 9, accessed September 20, 2017 at http://fortune.com/2017/06/09/retail-store-closings-ecommerce/.

Walmart (2010), 'Organizational Change Memo Regarding E-commerce from Eduardo Castro-Wright', January, accessed September 20, 2017 at http://corporate.walmart.com/_ news_/organizational-change-memo-regarding-e-commerce-from-eduardo-castro-wright2010.

Wigglesworth, Robin (2017), 'Will the Death of US Retail Be the Next Big Short?', The Financial Times, July 16. 
Katrijn Gielens and Els Gijsbrechts - 9781786430281 Downloaded from PubFactory at 04/26/2023 06:01:04AM 